\title{
VIVENCIANDO O PROCESSO CIRÚRGICO: PERCEPÇÃO E SENTIMENTOS DA CRIANÇA
}

\author{
EXPERIENCING THE SURGICAL PROCESS: \\ THE CHILD'S PERCEPTION AND FEELINGS
}

\section{VIVENCIANDO EL PROCESO QUIRÚRGICO: PERCEPCIÓN Y SENTTIMIENTOS DEL NIÑO}

\author{
Nayara Ruas Cardoso \\ Patrícia Fernandes do Prado ${ }^{2}$ \\ Ana Augusta Maciel Souza ${ }^{2}$ \\ Mirela Lopes Figueiredo ${ }^{2}$
}

Como citar este artigo: Cardoso NR, Prado PF, Souza AAM, Figueiredo ML. Vivenciando o processo cirúrgico: percepção e sentimentos da criança. Rev baiana enferm. 2017;31(3):e17648.

Objetivo: compreender a percepção e os sentimentos da criança que vivenciou o processo cirúrgico. Método: estudo descritivo com abordagem qualitativa, tendo como referencial teórico o Interacionismo Simbólico. Os participantes foram seis crianças com idade entre quatro e nove anos que se encontravam hospitalizadas em duas unidades de internação pediátrica. Os dados foram coletados no segundo semestre de 2015, por meio de entrevista semiestruturada, intermediada pelo Brinquedo Terapêutico. Resultados: os participantes expressaram seus sentimentos e percepções frente ao processo cirúrgico, os quais foram identificados em três categorias: Sentindo dor física e emocional, Conhecendo a dinâmica do processo cirúrgico e Tendo o desejo de voltar para a rotina. Conclusão: a cirurgia e a hospitalização são fatores que privam as crianças de suas atividades rotineiras e produzem experiências dolorosas e desagradáveis, desencadeando sentimentos variados, como ansiedade, medo do desconhecido e da morte.

Descritores: Cirurgia. Jogos e brinquedos. Hospitalização. Criança.

Objective: to understand the perception and feelings of children who experienced the surgical process. Method: descriptive study with a qualitative approach, in the theoretical framework of Symbolic Interactionism. The participants were six children between four and nine years old who were hospitalized at two pediatric inpatient units. The data were collected in the second semester of 2015 through a semistructured interview, intermediated by Therapeutic Play. Results: the participants expressed their feelings and perceptions of the surgical process, which were identified in three categories: Feeling physical and emotional pain, Getting to know the dynamics of the surgical process and Wanting to get back to routine. Conclusion: surgery and hospitalization are factors that deprive the children of their routine activities and produce painful and unpleasant experiences, triggering different feelings, such as anxiety, fear of the unknown, and death.

Descriptors: Surgery. Play and playthings. Hospitalization. Child.

\footnotetext{
Enfermeira. Residente do Programa em Saúde da Mulher do Departamento de Enfermagem da Universidade Estadual de Montes Claros. Montes Claros, Minas Gerais, Brasil.

2 Enfermeiras. Mestres. Professoras do Departamento de Enfermagem da Universidade Estadual de Montes Claros. Montes Claros, Minas Gerais, Brasil. patyfprado@uol.com.br
} 
Objetivo: comprender la percepción y los sentimientos del niño que vivenció el proceso quirúrgico. Método: estudio descriptivo con enfoque cualitativo, teniendo como referencial teórico el Interaccionismo Simbólico. Los participantes fueron seis niños con edad entre los cuatro y nueve años, que se encontraban hospitalizados en dos unidades de internamiento pediátrico. Los datos fueron recolectados en el segundo semestre de 2015, a través de entrevista semiestructurada, intermediada por el Juguete Terapéutico. Resultados: los participantes expresaron sus sentimientos y percepciones delante del proceso quirúrgico, los cuales fueron identificados en tres categorias: Sintiendo dolor físico y emocional, Conociendo la dinámica del proceso quirúrgico y Teniendo el deseo de volver para la rutina. Conclusión: la cirugía y la hospitalización son factores que privan a los niños de sus actividades rutineras y producen experiencias dolorosas y desagradables, desencadenando diversos sentimientos, como la ansiedad, el miedo de lo desconocido y de la muerte.

Descriptores: Cirugía. Juegos y juguetes. Hospitalización. Niño.

\section{Introdução}

A hospitalização é vista como uma situação extremamente perturbadora na vida de qualquer ser humano e tem contornos especiais quando se trata de um acontecimento na infância, pois as crianças ficam imersas em um ambiente novo, repleto de restrições e rotinas, com pessoas desconhecidas. Além disso, são submetidas a procedimentos geradores de medo e dor ${ }^{(1)}$.

O ingresso ao hospital para intervenção cirúrgica pode ser mais marcante para as crianças, tornando-se, muitas vezes, uma experiência incompreensível e traumatizante. A cirurgia é uma experiência que traz consigo exames incômodos, contatos com sangue, mal-estar, procedimentos anestésicos e dificuldades pós-operatórias, dentre outros eventos ${ }^{(2)}$.

A equipe de saúde, em especial a enfermagem, deve estar preparada para atender a criança em situação pós-cirúrgica, reconhecendo que esta encontra-se duplamente doente, uma vez que vivenciou a internação e o estresse da cirurgia ${ }^{(3)}$. Assim, cabe à enfermagem protagonizar o cuidado à saúde, antecipando-se aos efeitos estressores, pela utilização de intervenções primárias. Para tanto, é necessário ouvir as crianças para apreender a dimensão da doença em sua vida e o modo como é vivida, já que esses aspectos são singulares para cada criança ${ }^{(4)}$.

O planejamento do cuidado a essa clientela deve garantir o respeito e a dignidade da criança e de sua família em todas as etapas, incluindo-se a atenção não somente à saúde física, mas também aos cuidados com as necessidades emocionais e sociais que o infante apresenta, considerando-o como um ser em crescimento e desenvolvimento cuja autonomia deve ser incentivada. É possível afirmar que as crianças são as melhores fontes de informação sobre suas experiências e sentimentos. Elas podem expressar seus pensamentos de diferentes formas (verbal e não verbal). Para tanto, é necessário à enfermagem adentrar no universo infantil e permitir que expressem as situações vivenciadas ${ }^{(5)}$.

A utilização do Brinquedo Terapêutico (BT) é um recurso que tem merecido destaque na literatura, por ter se mostrado uma estratégia-chave para o envolvimento da criança na compreensão do seu processo de saúde-adoecimento, permitindo aos profissionais de enfermagem atuar de forma humanizada, respeitando o meio de comunicação mais eficaz da criança, o brincar ${ }^{(6)}$. $\mathrm{O}$ uso rotineiro do BT em unidades pediátricas fundamenta-se na importância de informar às crianças sobre a necessidade da hospitalização. Com isso, esse método contribui para amenizar a ansiedade, fazendo com que elas se sintam seguras e capazes de confiar no adulto que lhes presta cuidados ${ }^{(7)}$. Seu uso é regulamentado pelo Conselho Federal de Enfermagem (COFEN), por meio da Resolução n. 295/2004, que afirma, em seu primeiro artigo, que compete ao enfermeiro atuante na área pediátrica, como membro de uma equipe multiprofissional, a utilização do BT na assistência à criança e à família ${ }^{(8)}$.

Em contextos de atenção à saúde pediátrica, a área de enfermagem carece de estudos que 
contribuam para a sistematização da prática profissional em relação ao cliente cirúrgico. Deste modo, pesquisas nesse campo são relevantes, considerando-se a incidência de cirurgias na infância, e as reações das crianças hospitalizadas nessas circunstâncias. Nesse sentido, o presente estudo teve como questionamentos: Qual é a percepção da criança sobre a cirurgia? Quais os sentimentos manifestados pelo infante frente ao procedimento cirúrgico?

Buscar o conhecimento acerca da percepção e dos sentimentos expressos por essa clientela, utilizando o BT como ferramenta de intervenção, auxilia o profissional de enfermagem a compreender suas necessidades não somente fisiológicas, mas de todo o seu universo, podendo contribuir para o planejamento de um cuidado integral e humanizado, tornando essa experiência menos assustadora e traumática. O objetivo deste estudo foi compreender a percepção e os sentimentos da criança que vivenciou o processo cirúrgico.

\section{Métodos}

Trata-se de estudo descritivo exploratório, com abordagem qualitativa. A pesquisa qualitativa responde a questões que dão ao ser humano a oportunidade de refletir sobre o agir, pensar e partilhar com seus semelhantes com base na realidade vivida ${ }^{(9)}$. O referencial metodológico foi baseado no Interacionismo Simbólico (IS), perspectiva de análise das experiências humanas que tem como foco de estudo a natureza da interação, isto é, as atividades de dinâmica social que acontecem entre as pessoas ${ }^{(10)}$.

Os dados foram coletados no segundo semestre de 2015 em duas unidades de internação pediátrica na cidade de Montes Claros, Minas Gerais, Brasil. Participaram da pesquisa seis crianças com idade entre quatro e nove anos, selecionadas pelos seguintes critérios de inclusão: crianças em idade escolar (para que fossem capazes de verbalizar suas opiniões por meio da entrevista) de ambos os sexos; que estavam internadas, passando por seu primeiro procedimento cirúrgico; em pós-operatório mediato (período que decorre após 24 horas da cirurgia até o momento da alta hospitalar); capazes de brincar e interagir com o meio ambiente, cujos responsáveis legais autorizassem sua participação. Excluíram-se aquelas que estivessem sem acompanhante durante a internação ou que apresentavam incapacidade para responder às questões do estudo.

O número de participantes foi delimitado no decorrer da pesquisa, visto que o critério para interrupção da coleta de dados foi a "saturação dos dados", definida como a suspensão da inclusão de novos participantes a partir do momento em que os dados passam a apresentar certo grau de redundância $^{(11)}$.

A estratégia utilizada para a coleta de dados foi a entrevista individual, semiestruturada, gravada por meio eletrônico, intermediada pelo Brinquedo Terapêutico Dramático (BTD). A escolha do método decorreu de o BTD ser um recurso que permite a descarga emocional, expressão dos sentimentos, desejos e experiências vividas $^{(12)}$, permitindo aos profissionais captar o sentido que a experiência teve para o infante.

As indagações para dar início à sessão do BT foram: "Vamos brincar de uma criança que passou por uma cirurgia?"; "Você me conta uma história?".

O método utilizado para análise dos dados foi a análise qualitativa de conteúdo, seguindo as etapas de codificação e categorização. A categorização consiste na releitura dos códigos, classificando-os e agrupando-os por similaridade, segundo suas características conceituais, determinando as categorias temáticas representativas do fenômeno estudado ${ }^{(13)}$.

O projeto de pesquisa que originou este trabalho foi aprovado pelo Comitê de Ética em Pesquisa (CEP) da Universidade Estadual de Montes Claros (Unimontes), em cumprimento à Resolução n. 466/2012 do Conselho Nacional de Saúde ${ }^{(14)}$, sob o Parecer número 572/2014. Foi solicitado às crianças o assentimento para participar deste estudo por meio da assinatura do Termo de Assentimento Informado, e seus responsáveis também consentiram essa participação, assinando o Termo de Consentimento 
Livre e Esclarecido (TCLE), apresentado antes do início da pesquisa.

Com a finalidade de manter o anonimato dos participantes do estudo e para melhor compreensão dos resultados, às crianças foram atribuídos nomes fictícios extraídos da história infantil "A turma da Mônica", escolhidos aleatoriamente pelas pesquisadoras. As principais características dos participantes estão descritas no Quadro 1.

Quadro 1 - Principais características dos participantes do estudo

\begin{tabular}{|l|l|}
\hline Participantes & \multicolumn{1}{c|}{ Principais características } \\
\hline Magali & $\begin{array}{l}\text { Menina, } 6 \text { anos, submetida a tratamento cirúrgico de fratura exposta no membro } \\
\text { superior. Primeiro dia de pós-operatório. Primeira internação hospitalar. }\end{array}$ \\
\hline Cebolinha & $\begin{array}{l}\text { Menino, 9 anos, submetido a tratamento cirúrgico de drenagem de adutores. } \\
\text { Primeiro dia de pós-operatório. Primeira internação hospitalar. }\end{array}$ \\
\hline Anjinho & $\begin{array}{l}\text { Menino, } 4 \text { anos, submetido a cirurgia de hipospádia. Primeiro dia de pós-operatório. } \\
\text { Primeira internação hospitalar. }\end{array}$ \\
\hline Cascão & $\begin{array}{l}\text { Menino, } 9 \text { anos, submetido a tratamento cirúrgico de fratura da perna. Segundo dia } \\
\text { de pós-operatório. Primeira internação hospitalar. }\end{array}$ \\
\hline Mônica & $\begin{array}{l}\text { Menina, 9 anos, submetida a tratamento cirúrgico de fratura de rádio. Primeiro dia } \\
\text { de pós-operatório. Primeira internação hospitalar. }\end{array}$ \\
\hline $\begin{array}{l}\text { Gatinha } \\
\text { Mingau }\end{array}$ & $\begin{array}{l}\text { Menina, 7 anos, realizou apendicectomia. Segundo dia de pós-operatório. Primeira } \\
\text { internação hospitalar. }\end{array}$ \\
\hline
\end{tabular}

Fonte: Elaboração própria.

\section{Resultados e discussão}

A análise das entrevistas possibilitou a construção de três categorias temáticas que expressavam os sentimentos e as percepções das crianças frente ao processo cirúrgico: Sentindo dor física e emocional, Conhecendo a dinâmica do processo cirúrgico e Tendo o desejo de voltar para a rotina.

\section{Sentindo dor física e emocional}

O período pós-operatório foi relatado pelas crianças como um momento caracterizado pela dor, sendo o sinal mais referido por elas durante a sessão de BTD, conforme evidenciado nas seguintes falas:

A gente sente muita dor. (Mônica).

Ele chorou, porque doeu, e ele quer a mãe dele. (Anjinho).

Ele [boneco] tá sentindo dor. (Cascão).

Ele [boneco] chora muito, porque dói muito! (Cebolinha).

Só depois que ela [boneca] acordou, que sentiu dor. (Magali).
Estudo mostrou que a dor é constante na experiência cirúrgica vivida pela criança, estando presente de maneira mais evidente no período pós-operatório, de forma mais implícita na expectativa ou no medo do seu aparecimento. Pode estar presente até mesmo no sentimento de felicidade pela sua ausência ${ }^{(2)}$.

Outro estudo que investigou as memórias de crianças sobre a cirurgia eletiva à qual foram submetidas revelou que aquelas que tiveram um procedimento menos doloroso e acordaram sem dor tiveram memórias mais positivas. Todavia, as que sentiram mais dor, perderam e viram sangue, ou presenciaram o choro de sua mãe, tiveram memórias de que o hospital concedeu-lhes uma experiência ruim $^{(15)}$.

Pesquisa que objetivou explorar a experiência do manejo da dor pós-operatória da criança em idade escolar mostrou que ela é capaz de gerenciar a própria dor, sendo, portanto, importante para os cuidados em saúde valorizar o seu papel e utilizar estratégias que possibilitem liberdade para se comunicar. As crianças sugeriram aos pais que a presença deles e o uso de técnicas como distração poderiam melhorar a sua dor. Às 
enfermeiras, sugeriram que o uso de técnicas, como administração de medicamentos, distração e posicionamento, contribuíam para melhoria na gestão da dor ${ }^{(16)}$.

A colaboração da família no cuidado no pós-operatório de suas crianças é um fator que contribui para aliviar o estresse e o medo causados pela dor. À medida que os familiares são integrados no cuidado, há maiores possibilidades no trato da criança, pois se incorporam peculiaridades individuais que tornam a sistematização da assistência eficaz e eficiente ${ }^{(17)}$.

O procedimento cirúrgico, pela sua invasividade e incerteza quanto ao resultado, bem como o estresse presente no processo, combinado com ideias que a criança tem da doença e da cirurgia, desencadeia sentimentos variados no paciente, que podem incluir desde a sensação de alívio pelo diagnóstico da enfermidade até de agressão, impotência, isolamento, medo do desconhecido, da mutilação e da morte ${ }^{(2,18)}$. Nas crianças estudadas, tais sentimentos também estavam presentes, com destaque para o medo:

Ele [boneco] sentia cansado de ficar deitado. E eu senti um pouco de medo também [...] Medo da cirurgia, que ele tava sentindo muita dor. (Cebolinha).

Quando chegaram para me buscar, ela disse assim: Você que chama Mônica? Aí eu disse: Não. Eu me chamo Magali. Por que eu não queria ir pro bloco, para fazer a cirurgia. (Mônica).

O medo pode ser classificado em dois tipos: objetivo e subjetivo. Por sua vez, o medo objetivo pode ser subdividido em direto e indireto. O primeiro manifesta-se quando a experiência anterior, dolorosa ou desagradável, sofrida pela criança ocorreu em decorrência de ações provocadas no próprio tratamento. O medo objetivo indireto é oriundo de experiências ocorridas em ambientes semelhantes. O medo subjetivo advém por sugestões: crianças que ouviram falar de experiências desagradáveis vividas por seus pais, parentes ou amigos, ou especialidades afins ${ }^{(19)}$.

Emergiu também dos discursos das crianças o medo da morte. Referiram, durante a brincadeira, um possível risco de morte, se não fosse realizado o tratamento, e o medo desse desfecho em decorrência da cirurgia, conforme indicam as falas:

Porque tem que ficar de jejum para fazer a cirurgia e se ele [o boneco] não tomasse, ele podia desidratar e morrer. (Cebolinha).

Ele morreu e a médica colocou ele na cadeia. (Anjinho).

Tio eu vou acordar depois né? Não vou dormir para sempre, né? (Gatinha Mingau).

A morte é vista como uma realidade para a criança que transita entre a possibilidade de enfrentamento e o temor de que, mesmo com todos os cuidados, não consiga vencer a doença e a morte surja como resultado final. Tal aspecto é importante de ser considerado, pois, ao reconhecer a presença da angústia com relação à morte, é possível escutá-la como parte da vivência da criança no contexto hospitalar ${ }^{(20)}$.

O medo associado à falta de informações e de preparo da criança pode suscitar fantasias relacionadas ao entendimento da necessidade da cirurgia ${ }^{(7)}$. A falta de preparação pode ocorrer, seja pela ausência de um programa educacional pré-operatório, seja pela ausência de compreensão da equipe profissional de que a criança tenha capacidade para lidar com situações ansiogênicas e compreender a situação pela qual está passando. $O$ infante, quando preparado, pode colaborar no seu processo de recuperação, devido ao fato de entender e, para tanto, saber como lidar com possíveis reações $^{(15)}$.

Assim, autores têm reforçado a importância do preparo emocional das crianças e de seus familiares para as diferentes etapas de um procedimento cirúrgico, com vistas à prevenção do risco de desenvolvimento e minimização dos efeitos negativos dessas experiências ${ }^{(2,7,15,18)}$.

Percebeu-se ainda que as crianças sentiam-se agredidas pelos objetos que eram utilizados nos procedimentos aos quais foram submetidas, como aqueles que envolviam a utilização de agulhas, podendo vir a entender essa situação como um castigo por não se comportarem bem. Além disso, observou-se, durante a brincadeira, alguns sentimentos de ameaça e agressividade 
relacionados à figura dos profissionais de saúde, conforme evidenciado nos discursos:

\section{A menininha [boneca] ficou teimosa e tomou uma agu- lha. (Anjinho).}

Essa é uma médica [boneca de jaleco]. Ela dá injeção nela [boneca] [...] Porque ela [médica] não gosta dela. (Anjinho)

Esse aqui [arma de brinquedo] tira a tampinha enche de água, ai a gente aperta assim para a gente acertar na pessoa [...] na enfermeira. (Cascão).

Um dos eventos mais ameaçadores para o público infantil são os procedimentos invasivos, pois são percebidos como uma invasão bastante dolorosa em seu corpo. Agulhas e injeções consistem no principal alvo de reclamações. Além de dolorosos, são vistos também como traumáticos, como atos hostis e mutiladores ${ }^{(21)}$. O enfrentamento dessas situações faz com que as crianças apresentem desconforto, medo e ansiedade, além de desenvolverem reações agressivas e de rejeição com os profissionais de saúde envolvidos em sua assistência. A fim de amenizar esses impactos, é colocada a necessidade de as crianças serem preparadas para a realização dos procedimentos, principalmente quando se tratar de uma experiência nova. O BT Instrucional destaca-se para expor o conhecimento sobre o que realmente irá acontecer ${ }^{(12,21)}$.

\section{Conbecendo a dinâmica do processo cirúrgico}

As crianças trouxeram para o BTD elementos referentes à sua experiência de estarem no centro cirúrgico, relatando os procedimentos realizados na sala de operação, dentro do contexto da brincadeira, como evidenciado nos discursos:

\footnotetext{
O médico falou que ela [boneca] iria fazer cirurgia e ela ficou internada. A mãe dela [da boneca] ficou com ela na cadeira. Ai , depois, a doutora [boneca de jaleco azul] chegou, e a mãe dela estava acordada e a menininha [boneca] dormindo. Ai a doutora falou que tinha que aplicar a injeção na menininha. (Magali).

O André [boneco] colocou uma touca na cabeça, e uma dessa em cada pé, e continuou com esse negócio no braço. Aí, quando chegou lá, ele deitou e a enfermeira [boneca de jaleco branco] colocou tipo um escorador aqui [no braço]. Ah, não! Antes ele [boneco] ficou sentado e aplicou uma anestesia nas costas. Eles [médicos] deu o remédio para dormir. Aí ele [boneco] dormiu do começo até o fim da cirurgia, que gastou 50 minutos a cirurgia.
}

Ai, quando acabou a cirurgia, o André [boneco] foi para outra sala, sem ser a que ele estava, e ficou tomando soro e depois um pouco de água e logo após ele voltou pro leito que ele estava. (Cebolinha).

Ela pôs o negócio e pôs uma fita. Aí eu fiquei chorando. Ai ela foi e me deu outra injeção no braço. Era a anestesia. Ela falou 1, 2, 3 e você fecha o olbo viu? Ai foi 1, 2, 3, eu fechei o olbo e de repente eu dormi. Aí, quando eu dormi, tava muito ruim, eu não vi nada. Aí eles disse assim que eu não tava falando coisa com coisa quando eu estava dormindo. Ela tava me perguntando se tava doendo, e eu respondia, mas eu estava dormindo. Aí depois eles cortaram o meu braço e pôs ponto. (Mônica).

A projeção sobre a realidade exterior representada no brincar possibilita à criança a oportunidade de elaborar melhor a situação vivenciada e exprimir suas emoções, permitindo aos profissionais de saúde trabalharem a percepção do infante acerca de um acontecimento, de maneira a tornar esse período o menos traumático possível. Assim, por meio da brincadeira, a criança poderia repetir aquilo que, para ela, na sua fantasia, seria a sua cirurgia, na tentativa de dominar uma experiência vivenciada de forma passiva e atribuir-lhe significado ${ }^{(22)}$.

$\mathrm{Na}$ fala de outra participante, percebeu-se que a cirurgia constituiu-se em uma experiência traumatizante, carregada de sentimento de ameaça à sua integridade física. Além disso, sua carga emocional referente ao fato de que foi enganada pela mãe sobre a intervenção cirúrgica é retratada no fragmento a seguir:

Tia, mamãe mentiu para mim, e eu fiquei chateada. Ela falou que não ia cortar. Ai, quando eu acordei, eu vi tia. Deu até pontinho! (Gatinha Mingau).

É importante desmistificar a ideia de que a criança não é capaz de compreender aquilo que se passa com ela e que é incapaz de lidar com determinadas situações, como uma cirurgia. Informar de maneira clara sobre a necessidade da hospitalização e da cirurgia contribui para amenizar a ansiedade, fazendo com que se sinta segura e capaz de confiar no adulto que cuida dela. Pais e profissionais têm dificuldade para transmitir essas informações, omitindo frequentemente a verdade, na tentativa de poupá-la e não lhe causar sofrimento. Quando esta situação acontece, a confiança da criança nos adultos que cuidam dela pode ser abalada. Assim, torna-se importante que os pais sejam envolvidos no preparo da criança, porque 
ela validará as informações recebidas junto a eles, que são sua fonte de segurança ${ }^{(7)}$.

\section{Tendo o desejo de voltar para a rotina}

Os participantes reconheceram a necessidade de estarem no hospital para sua recuperação. Ao mesmo tempo, projetaram, durante a brincadeira, a vontade de deixar o ambiente hospitalar e voltar para casa. A expectativa de retornar à rotina quebrada pela internação, reencontrar os amigos e pessoas que fazem parte do seu dia a dia, é representada.

Ela vai tomar injeção para ir embora. (Anjinho).

Eles ficaram bom. Foram para casa deles e, na casa deles, eles foram para escola, brincaram. (Cascão).

Ela [boneca] ficou dormindo e depois ficou boa. Ela foi para casa, porque em casa ela podia ir na escola e ver a professora dela, que ela estava com saudade. (Magali).

Desde o dia que ele entrou no hospital, ele [boneco] tava querendo ir [para casa], mas ele teve que vir para sarar a dor. Depois de três, quatro dias, ele voltou para casa, brincou com o primo dele. (Cebolinha).

A hospitalização representa, para a criança que se encontra em fase de socialização, uma situação diferente de todas já vivenciadas, haja vista que sua rotina é modificada, ocorrendo ruptura com o seu meio social, suas atividades, seus hábitos e costumes ${ }^{(23)}$. Na maior parte do tempo, a criança internada fica restrita ao leito, passiva, cercada de pessoas estranhas, vivenciando procedimentos dolorosos e desagradáveis ${ }^{(7)}$.

O súbito afastamento produz grande sofrimento para esse público. Apesar de ser capaz de tolerar breves períodos de separação e desenvolver confiança em outros adultos significativos nessa fase, ela não consegue enfrentar a situação diante do estresse causado pela doença e pelo tratamento, podendo mostrar-se retraída, chorosa, recusando-se a cooperar em atividades habituais de autocuidado ${ }^{(24)}$.

É nesta perspectiva que nasce a importância do desenvolvimento das ações lúdicas com as crianças que se encontram limitadas ao ambiente hospitalar. O brinquedo e o brincar possuem importante valor terapêutico e educativo para esse público durante a hospitalização, pois restabelecem o físico e o emocional, tornando o ambiente hospitalar menos traumatizante e mais alegre, proporcionando condições melhores para a sua recuperação ${ }^{(24)}$.

\section{Conclusão}

A assistência à criança que é submetida a cirurgia compreende particularidades que desafiam não só a equipe de enfermagem, mas toda a equipe de saúde, englobando elementos referentes à própria criança, aos seus familiares e aos profissionais de saúde. A atenção e o cuidado desses profissionais numa abordagem integral e humanizada devem, principalmente, amenizar o sofrimento da criança, oferecendo-lhe recursos que a ajudem a enfrentar, de maneira menos traumática possível, a situação vivenciada.

Neste estudo, a utilização do BT permitiu dar espaço e oportunidades para as crianças exprimirem seus sentimentos e conflitos vivenciados em relação à hospitalização e à intervenção cirúrgica. Os resultados evidenciaram que a hospitalização, para esse público, é vista e caracterizada por uma série de mudanças em sua rotina, as quais desencadeiam os sentimentos de medo, ansiedade e afastamento de pessoas significativas. A dor e o desconforto físico advindos do procedimento cirúrgico permeiam a vida dessas crianças, tornando o processo de hospitalização ainda mais traumático. Além disso, existe a preocupação da criança com as mudanças na sua imagem corporal e até mesmo com a condição de morte. Desse modo, conclui-se que a cirurgia e a hospitalização são fatores que privam as crianças de suas atividades rotineiras e produzem experiências dolorosas e desagradáveis, desencadeando sentimentos variados, como ansiedade, medo do desconhecido e da morte.

Ressalta-se a necessidade de realização de outros estudos para aprofundar o entendimento da complexidade dos significados da cirurgia para a criança, bem como comprovar a efetividade da utilização do BT nas diferentes etapas de atendimento dessa clientela dentro do contexto estudado. 


\section{Colaborações:}

1. concepção, projeto, análise e interpretação dos dados: Nayara Ruas Cardoso, Ana Augusta Maciel Souza, Patrícia Fernandes do Prado e Mirela Lopes Figueiredo;

2. redação do artigo e revisão crítica relevante do conteúdo intelectual: Nayara Ruas Cardoso, Ana Augusta Maciel Souza, Patrícia Fernandes do Prado e Mirela Lopes Figueiredo;

3. aprovação final da versão a ser publicada: Nayara Ruas Cardoso, Ana Augusta Maciel Souza, Patrícia Fernandes do Prado e Mirela Lopes Figueiredo.

\section{Referências}

1. Sousa LD, Gomes GC, Silva MRS, Santos CP, Silva BT. A família na unidade pediátrica: percepções da equipe de enfermagem acerca da dimensão cuidadora. Ciênc Enferm [Internet]. 2011 [cited 2015 Jun 25];17(2):87-95. Available from: http:// www.scielo.cl/pdf/cienf/v17n2/art_10.pdf

2. Garanhani ML, Valle ERM. O significado da experiência cirúrgica para a criança. Ciênc Cuid Saúde [Internet]. 2012 [cited 2016 July 21];11:25966. Available from: http://dx.doi.org/10.4025/ cienccuidsaude.v11i5.17084

3. Fernandes SC, Arriaga P, Esteves F. Atitudes infantis face aos cuidados de saúde e percepção de dor: papel mediador dos medos médicos. Ciênc saúde coletiva [Internet]. 2014 jul [cited 2015 Aug 21];19(7):2073-82. Available from: http://www.scielo.br/scielo.php?script=sci arttext\&pid=S141381232014000702073\&lng=en.http:// dx.doi.org/10.1590/1413-81232014197.08992013

4. Vasques RCY, Bousso RS, Mendes-Castillo AMC. A experiência de sofrimento: histórias narradas pela criança hospitalizada. Rev Esc Enferm USP [Internet]. 2011 [cited 2016 Feb 12];45(1):120-6. Available from: http://www.scielo.br/pdf/reeusp/ v45n1/en_17.pdf

5. Vasques RCY, Castilho AMCM, Bousso RS, BorghiCA, Sampaio OS. Dando voz às crianças: considerações sobre a entrevista qualitativa em pediatria. REME Rev Min Enferm [Internet]. 2014 [cited 2016 Feb 11];18(4):1016-20. Available from: http://www. dx.doi.org/10.5935/1415-2762.20140075
6. Conceição CM, Ribeiro CA, Borba RIH, Ohara CVS, Andrade PR. Brinquedo terapêutico no preparo da criança para punção venosa ambulatorial: percepção dos pais e acompanhantes. Esc. Anna Nery [Internet]. 2011 Apr/Jun [cited 2016 Apr 16];15(2):346-63. Available from: http://www. scielo.br/scielo.php?script=sci_arttext\&pid=S141481452011000200018\&lng=en

7. Paladino CM, Carvalho R, Almeida FA. Brinquedo terapêutico no preparo para a cirurgia: comportamentos de pré-escolares no período transoperatório. Rev Esc Enferm USP [Internet]. 2014 June [cited 2015 Aug 20];48(3):423-9. Available from: http://www.scielo.br/scielo.php?script=sci_ arttext\&pid $=S 008062342014000300423 \& \operatorname{lng}=e n$. http://dx.doi.org/10.1590/S0080-623420140000300006

8. Conselho Federal de Enfermagem. Resolução n. 295/2004, de 24 de outubro de 2004. Dispõe sobre a utilização da Técnica do Brinquedo/Brinquedo Terapêutico pelo enfermeiro na assistência prestada à criança e família hospitalizadas [Internet]. Rio de Janeiro; 2004 [cited 2016 Feb 5]. Available from: http://novo.portalcofen.gov.br/ resoluo-cofen-2952004_4331.html

9. Minayo MCS. O desafio do conhecimento. Pesquisa qualitativa em saúde. 13a ed. São Paulo: Hucitec; 2013.

10. Charon JM. Symbolic interacionism: an introduction, an interpretation, an integration. Englewood Cliffs (NJ): Prentice-Hall; 2009.

11. Fontanella BJB, Luchesi BM, Saidel MGB, Ricas J, Turato ER, Melo DM. Amostragem em pesquisas qualitativas: proposta de procedimentos para constatar saturação teórica. Cad Saúde Pública [Internet]. 2011 [cited 2016 Feb 11];27(2):389-94. Available from: http://www.scielo.br/pdf/csp/ v27n2/20.pdf

12. Francischinelli AGB, Almeida FA, Fernandes DMSO. Uso rotineiro do brinquedo terapêutico na assistência a crianças hospitalizadas: percepção de enfermeiras. Acta paul enferm [Internet]. 2012 [cited 2017 June 4];25(1):18-23. Available from: http://www.scielo.br/scielo.php?script=sci arttext\&pid=S0103-21002012000100004\&lng=en

13. Bardin L. Análise de conteúdo. Lisboa: Edições 70; 2011.

14. Brasil. Ministério da Saúde. Conselho Nacional de Saúde. Resoluçãon. 466, de 12 de dezembro de 2012. Estabelece diretrizes e normas regulamentadoras de pesquisas envolvendo seres humanos. Brasília; 
2012 [cited 2017 June 5]. Available from: http:// bvsms.saude.gov.br/bvs/saudelegis/cns/2013/ res0466_12_12_2012.html

15. Broering CV, Crepaldi MA. O estudo das memórias pós-cirúrgicas: importância e limitações. Vittalle, Rio Grande [Internet] 2013 [cited 2017 June 4];25(2):53-61. Disponível em: https://www.seer. furg.br/vittalle/article/view/6027/3727

16. Sng QW, Taylor B, Liam JLW, Klainin-Yobas P, Wang W, He HG. Postoperative pain management experiences among school-aged children: a qualitative study. J Clin Nurs [Internet]. 2013 [cited 2016 Feb 11];22:958-68. Available from: http:// onlinelibrary.wiley.com/doi/10.1111/jocn.12052/ abstract

17. Alves BA, Santos TFM, Ferrari RAP, Tacla MTGM, Sant'Anna FL, Lopes EB. Criança hospitalizada: caracterização dos procedimentos cirúrgicos em um hospital escola público. Semina ciênc biol saúde [Internet] 2015 Ago [cited 2016 July 21];36(1):317-24. Available from: http://dx.doi. org/10.5433/1679-0367.2015v36n1Suplp317

18. Pfeifer PM, Quintana AM. O ato cirúrgico e as fantasias infantis: uma revisão da literatura. Mudanças [Internet] 2015 jul-dez [cited 2016 Feb 11];23(2):9-16. Available from: file:///C:/Users/ user/Downloads/5769-22797-2-PB\%20(1).pdf

19. Marques KBG, Gradvohl MPB, Maia MCG. Medo e ansiedade prévios à consulta odontológica em crianças do município de Acaraú - CE. Rev bras promoç. saúde [Internet] out-dez 2010 [cited 2016 July 15];23(4):358-67. Available from: http://www. unifor.br/images/pdfs/rbps/artigo08_2010.4.pdf
20. Quintana AM, Arpini DM, Pereira CRR, Santos MS. A vivência hospitalar no olhar da criança internada. Ciênc cuid saúde [Internet] 2007 out/dez [cited 2015 Mar 20];6(4):414-23. Available from: http:// dx.doi.org/10.4025/cienccuidsaude.v6i4.3679

21. Souza LPS, Silva RKP, Amaral RG, Souza AAM, Mota ÉC, Silva CSO. Câncer infantil: sentimentos manifestados por crianças em quimioterapia durante sessões de brinquedo terapêutico. RENE rev min enferm [Internet]. 2012 [cited 2017 May 4];13(3):686-92. Available from: http://dx.doi. org/10.15253/rev\%20rene.v13i3.4010

22. Lerwick JL. Psychosocial implications of pediatric surgical hospitalization. Semin Pediatr Surg [Internet]. 2013 Aug [cited 2017 May 4];22(3):12933. Available from: http://www.sempedsurg.org/ article/S10558586(13)00034-6/fulltext

23. Santos PM, Silva LF, Dpianti JRB, Cursino EG, Ribeiro CA. Os cuidados de enfermagem na percepção da criança hospitalizada. Rev bras enferm [Internet]. 2016 jul-ago [cited 2017 May 4];69(4):646-53. Available from: http://dx.doi. org/10.1590/0034-7167.2016690405i

24. Motta AB, Perosa GB, Barros L, Silveira KA, Lima ASS, Carnier LE, et al. Comportamentos de coping no contexto da hospitalização infantil. Estud psicol (Campinas) [online]. 2015 [cited 2017 May 6];32(2):331-41. Available from: http://dx.doi. org/10.1590/0103-166X2015000200016

Recebido: 30 de agosto de 2016

Aprovado: 16 de agosto de 2017

Publicado: 30 de outubro de 2017 